\title{
Mixed Hepatoblastoma with Teratoid
}

\section{Features}

National Cancer Institute

\section{Source}

National Cancer Institute. Mixed Hepatoblastoma with Teratoid Features. NCI

Thesaurus. Code C7098.

A hepatoblastoma characterized by the presence of mixed epithelial and mesenchymal components and additional tissues such as striated muscle, bone, epithelial tissues, and melanin pigment. 